\title{
A família Myrsinaceae nos contrafortes do Maciço da Tijuca E ENTORNO DO JARDIM BOTÂNICO do RIO DE JANEIRO, BRASIL
}

\author{
Maria de Fátima Freitas ${ }^{1,3}$ \& Tatiana Tavares Carrijo ${ }^{2}$
}

\begin{abstract}
Resumo
(A família Myrsinaceae nos contrafores do Maciço da Tijuca e entorno do Jardim Botânico do Rio de Janeiro, Brasil) Myrsinaceae está representada no Brasil pelos gêneros Ardisia, Cybianthus, Myrsine e Stylogyne. Como parte dos estudos para a flora do estado do Rio de Janeiro, o presente trabalho apresenta o levantamento das espécies de Myrsinaceae ocorrentes nos contrafores do Maciço da Tijuca, incluindo os trechos de floresta urbana adjacentes ao Jardim Botânico do Rio de Janeiro. São descritas e ilustradas as seguintes espécies: Ardisia compressa, A. humilis, A. solanacea, Cybianthus cuneifolius, Myrsine coriacea, M. guianensis, M. hermogenesii, M. umbellata, M. venosa, Stylogyne depauperata e S. laevigata.
\end{abstract}

Palavras-chave: Mata Atlântica, flora, taxonomia, Ardisia, Cybianthus, Myrsine, Stylogyne.

\section{Abstract}

(Family Myrsinaceae in the Maciço da Tijuca and vegetation adjacent to the Jardim Botânico do Rio de Janeiro, Brazil) The Myrsinaceae are represented in Brazil by the following genera: Ardisia, Cybianthus, Myrsine and Stylogyne. As part of the studies for the flora of the state of Rio de Janeiro, this work presents the species of Myrsinaceae which occurs in the Maciço da Tijuca and vegetation adjacent to Rio Botanical Garden. The species described and illustrated are: Ardisia compressa, A. humilis, A. solanacea, Cybianthus cuneifolius, Myrsine coriacea, M. guianensis, M. hermogenesii, M. umbellata, M. venosa, Stylogyne depauperata and S. laevigata.

Key words: Atlantic forest, flora, taxonomy, Ardisia, Cybianthus, Myrsine, Stylogyne.

\section{INTRODUÇÃO}

A família Myrsinaceae apresenta distribuição pantropical, e cerca de 1.500 espécies, subordinadas a 49 gêneros (Ståhl \& Anderberg 2004). No Brasil ocorrem os gêneros Ardisia, Cybianthus (incl. Conomorpha), Myrsine (incl. Rapanea) e Stylogyne, totalizando cerca de 100 espécies (Jung-Mendaçolli et al. 2005).

As espécies de Myrsinaceae são árvores, mais freqüentemente arbustos, de folhas simples, alternas, sem estípulas, freqüentemente adensadas no ápice dos ramos, apresentando, geralmente, estruturas secretoras internas que podem ser encontradas nas flores e frutos (Barroso et al. 2002).

As espécies de Ardisia, por seu caráter ornamental, são amplamente utilizadas no paisagismo (Heywood 1993), enquanto que as espécies nativas de Myrsine destacam-se em processos naturais de sucessão (Tabarelli \& Mantovani 1997; Dornelles \& Negrelle 2000) e como importante recurso alimentar para a avifauna (Pineschi 1990, Silva \& Tabarelli 2000). No entanto, pouco é conhecido a respeito dos potenciais de uso e comercialização das espécies brasileiras de Myrsinaceae, principalmente dos gêneros Cybianthus e Stylogyne.

O primeiro estudo sobre as espécies do gênero Myrsine (=Rapanea) que ocorrem na Mata Atlântica no estado do Rio de Janeiro foi apresentado por Siqueira (1993). Jung-Mendaçolli \& Bernacci $(1997,2001)$ e Jung-Mendaçolli et al. (2005) redescreveram espécies citadas por Mez (1902) em floras locais do sudeste brasileiro, principalmente do estado de São Paulo, enquanto Freitas \& Kinoshita (2004, 2005) enfocaram seus estudos em espécies de Myrsine do Sudeste e Sul do Brasil. Ainda assim, dados sobre táxons brasileiros de Myrsinaceae são escassos e insuficientes frente a grande diversidade existente.

Artigo recebido em 09/2007. Aceito para publicação em 11/2008.

${ }^{1}$ Instituto de Pesquisas Jardim Botânico do Rio de Janeiro, R. Pacheco Leão 915, 22460-030, Rio de Janeiro, RJ, Brasil. ${ }^{2}$ Instituto de Pesquisas Jardim Botânico do Rio de Janeiro, Escola Nacional de Botânica Tropical, Bolsista CAPES-Doutorado.

${ }^{3}$ Autor para correspondência: ffreitas@jbrj.gov.br 
Aublet (1775) descreveu o gênero Rapanea distinguindo-o de Myrsine pela presença de anteras completamente sésseis ao tubo da corola. Este conceito foi seguido por Mez (1902). Autores subsequentes que analisaram espécies da América do Sul e Ásia (Hosaka 1940; Pipoly 1991, 1996; Pipoly \& Chen 1995; Otegui 1998; Freitas \& Kinoshita 2005) descreveram variações no androceu, como a presença de filetes reduzidos e/ou parcialmente livres do tubo da corola. Estes autores questionaram a distinção dos gêneros considerando Rapanea como sinônimo de Myrsine. Chen \& Pipoly (1996) esclareceram que, em uma visão mundial das espécies, este caráter não sustenta a circunscrição destes em gêneros distintos. Otegui (1998), estudando as espécies do Cone Sul, realizou novas combinações de espécies ocorrentes no Brasil e novos ajustes também foram publicados por Freitas \& Kinoshita (2004) para espécies ocorrentes na Região Sudeste. Recentemente, Jackes (2005) corroborou com esta ampla circunscrição ao revisar as espécies de Myrsine da Austrália por observar filetes não adnatos à corola.

O presente trabalho visa contribuir para o conhecimento da família Myrsinaceae, apresentando o inventário das espécies ocorrentes em um trecho de floresta atlântica do estado do Rio de Janeiro.

\section{Material e Métodos}

A área de estudo compreende toda a formação de floresta urbana no entorno do Jardim Botânico do Rio de Janeiro, incluindo o Maciço da Tijuca. A área apresenta cobertura vegetal típica de Floresta Ombrófila Densa, com clima tropical quente e úmido, e elevados índices de pluviosidade (Silva et al. 1994).

Para a realização do inventário foram analisados materiais depositados nos herbários GUA, HB, R, RB e RFA (acrônimos segundo Holmgren et al. 1990). Incluiu-se, neste trabalho, as espécies cultivadas no arboreto do Jardim Botânico do Rio de Janeiro, pela ocorrência observada na vegetação adjacente.

São apresentadas descrições, ilustrações, chaves para identificação dos gêneros e espécies e comentários.

\section{Resultados e Discussão}

Dos gêneros de Myrsinaceae citados por Gentry (1996) para o Brasil, todos estão representados na região estudada, somando-se onze espécies, a saber: Ardisia compressa, A. humilis, A. solanacea, Cybianthus cuneifolius, Myrsine coriacea, M. guianensis, M. hermogenesii, M. umbellata, M. venosa, Stylogyne depauperata e S. laevigata.

\section{Chave para identificação dos gêneros de Myrsinaceae}

1. Inflorescências umbeliformes 3. Myrsine

1'. Inflorescências em racemos, panículas ou corimbos.

2. Flores em racemos, flores tetrâmeras 2. Cybianthus

2'. Flores em corimbos ou panículas, flores pentâmeras ou tetrâmeras.

3. Corola rotácea ou campanulada, estilete subulado, estigma puntiforme, ovário multiovulado. 1. Ardisia

3'. Corola campanulada, estilete cilíndrico, estigma capitado ou capitulado, ovário pauciovulado 4. Stylogyne

\section{Ardisia Sw.}

Arbustos ou árvores, monóicas. Ramos tomentosos ou glabros. Folhas pecioladas, atenuadas, com pontuações glandulares translúcidas ou nigrescentes, margem inteira ou levemente serrada. Inflorescências terminais, laterais ou axilares, em corimbos ou panículas corimbosas a subcorimbosas. Flores bissexuais 5-meras, cálice e corola contortos ou imbricados, pontuados. Estames livres entre si ou unidos formando um tubo estaminal; anteras rimosas ou poricidas, introrsas, 
basifixas ou dorsifixas. Estilete subulado ou cilíndrico, estigma puntiforme. Drupa esférica a esferoidal, monospérmica, embrião filiforme, oblíquo.
Ardisia possui entre 400-500 espécies de distribuição pantropical (Chen \& Pipoly 1996). No Brasil ocorrem cerca de 15 espécies (Miquel 1856).

\section{Chave para as espécies de Ardisia}

1. Corola campanulada; pétalas deflexas a revolutas, ápice arredondado a ligeiramente agudo . 1.1 A. compressa

1'. Corola rotácea; pétalas patentes, subpatentes à ligeiramente deflexas (nunca revolutas), ápice acuminado a abruptamente acuminados.

2. Pedicelos 8-9 mm compr.; sépalas com margem fimbriada; filetes curtos (cultivada).... 1.2 A. humilis

2'. Pedicelos 23-25 mm compr., sépalas com margem inteira, anteras sésseis (cultivada, subespontânea) 1.3 A. solanacea

1.1 Ardisia compressa Kunth in H.B.K., Nov. Gen. Sp. 3: 245. 1818.

Fig. 1a-d

Arbusto ca. $3 \mathrm{~m}$ alt. Ramos cilíndricos, 2,3-2,8 mm diâm., glabros, tomentosos nas porções jovens. Folhas cartáceas, elípticas a oboelípticas, $10,5-12 \times 3,8-4,4 \mathrm{~cm}$, base levemente atenuada, ápice acuminado, margem inteira a irregular; nervação campilódroma, face abaxial com pontuações cilíndricas, nigrescentes, visíveis; pecíolo 4-5 mm compr., glabro. Inflorescências terminais e laterais (axilares ou ramifloras), panículas corimbosas 3-ramificadas, brácteas caducas; pedúnculo 15,4-16,2 mm compr., glabros. Flores 5-6 mm compr., pedicelos 5-6 mm compr.; cálice cupuliforme, ca. 1,6 mm compr., lóbulos ca. $1,5 \times 1 \mathrm{~mm}$, cartáceos, triangulares, ápice agudo, com pontuações cilíndricas nigrescentes e alaranjadas, margem glanduloso-fimbriada, não hialina; corola campanulada, $5,5-5,7 \mathrm{~mm}$ compr., pétalas 4,4-4,6 × 1,5-1,7 mm, cartáceas, deflexas a revolutas, glabras, lóbulos elípticos, ápice arredondado a ligeiramente agudo, margem inteira, pontuações cilíndricas e lineares esparsas; estames ca. 3,2 mm compr., filetes ca. $1,7 \mathrm{~mm}$ compr., anteras linear-sagitadas, ca. 3,5 ×0,6 mm, coloração uniforme, rimosas, ápice agudo, apiculado, base cordada; gineceu ca. 6-6,2 mm compr., ovário ovado, ca. $1,2 \times 1 \mathrm{~mm}$, com muitas pontuações glandulares cilíndricas e lineares, multiovulado, estilete cilíndrico, ca. 4 mm compr., estigma puntiforme. Drupa ovato-depressa,
$6,5 \times 5,6 \mathrm{~mm}$, com pontuações cilíndricas e lineares proemimentes.

Ardisia compressa é originária da Venezuela e utilizada no Brasil como ornamental. São arbustos de crescimento em touceiras, com flores alvas, com anteras amarelas e frutos vistosos. Pode ser encontrada como subespontânea nas vegetações adjacentes ao arboreto do Jardim Botânico do Rio de Janeiro. Floresce de maio a junho e frutifica em julho e agosto.

Material examinado: arboreto do Jardim Botânico do Riode Janeiro, V.1991, fl.,J. C. Gomess.n. (RB 292082); 31.V.1999, fl., C. G. Pinto et al. 88 (RB); VII.1991, fr., N. M. F. Silva et al. s.n. (RB 292906); 27.VIII.1996, bot. e fl., L. C. Giordano et al. 2118 (RB).

1.2 Ardisia humilis Vahl, Symb. Bot. 3: 40. 1794.

Fig. 1e-g

Arbusto 3 a $4 \mathrm{~m}$ alt. Ramos cilíndricos, 1,6-2,5 mm diâm., glabros, com pontuações glandulares lineares. Folhas cartáceas, elípticas à elíptico-obovadas, $12-12,9 \times 4,2-4,8 \mathrm{~cm}$, base e ápice agudos, margem inteira; nervação campilódroma, face abaxial com pontuações nigrescentes em toda a extensão; pecíolo 6-7 mm compr., glabro. Inflorescências subterminais e axilares, panículas subcorimbosas, com 6-8 flores, brácteas caducas; pedúnculo ca. $9 \mathrm{~mm}$ compr. Flores 9-10 mm compr.; pedicelos 8$9 \mathrm{~mm}$ compr.; sépalas cartáceas, eretas, ca. $1,8 \times 2,5 \mathrm{~mm}$, ovadas, ápice arredondado, com pontuações cilíndricas nigrescentes, margem fimbriada, hialina; corola rotácea, pétalas ca. 

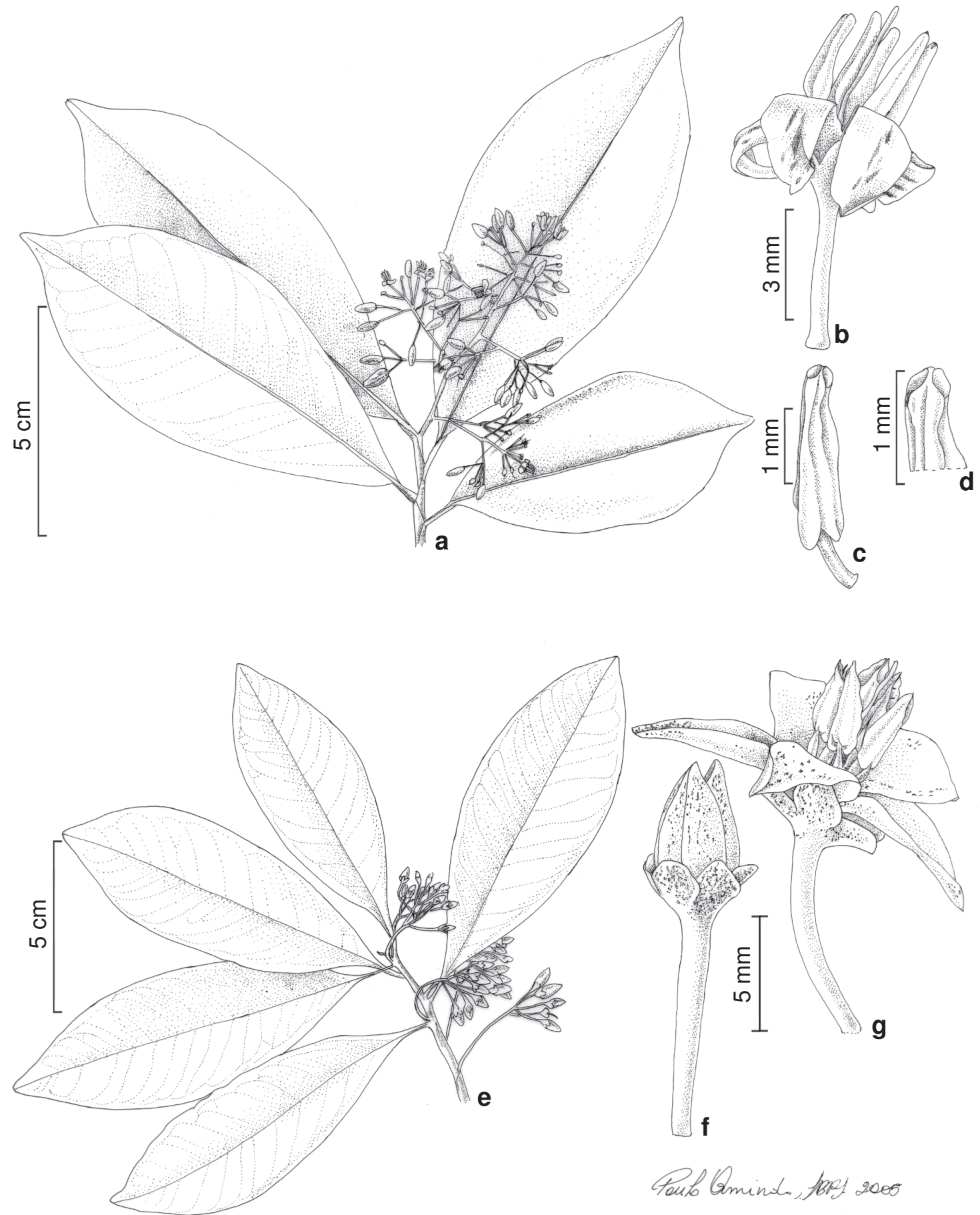

Figura 1 - a-d. Ardisia compressa Kunth - a. detalhe do ramo florífero; b. flor; c. antera; d. detalhe da antera com poro apical (Giordano 2118). e-g. Ardisia humilis Vahl - e. detalhe do ramo florífero; f. botão floral; g. flor (IRC.RCC 53). 
$9,5 \times 3,5 \mathrm{~mm}$, cartáceas, glabras; lóbulos elípticolanceolados, patentes, ápice acuminado, margem inteira, com pontuações lineares; estames ca. 4,3 mm compr., filetes ca. $0,5 \mathrm{~mm}$ compr., anteras sagitadas, sub-sésseis, ca. 3,8 $\times 1,2 \mathrm{~mm}$, rimosas; gineceu $6,5 \mathrm{~mm}$, ovário cônico, ca. $0,9 \times 1 \mathrm{~mm}$, multiovulado, estilete ca. $4,5 \mathrm{~mm}$ compr., com pontuações em toda extensão, estigma puntiforme. Drupa globosadepressa, 5,3 $\times 4,6 \mathrm{~mm}$, com pontuações lineares nigrescentes e proeminentes.

Ardisia humilis é originária da Ásia. No Brasil é utilizada como ornamental devido às suas flores róseas. Seus frutos roxos e vistosos são atrativos à avifauna, especialmente para os tucanos que habitam a área do Jardim Botânico. Floresce nos meses de agosto à dezembro e frutifica em dezembro e janeiro.

Material examinado: arboreto do Jardim Botânico do Rio de Janeiro, 29.I.1947, fl., J. G. Kuhlmann s.n. (RB 82887); 6.XII.1985, fl., IRC.RCC 53 (RB); 27.VIII.1996, fl. e fr., L. C. Giordano et al. 2177 (RB).

1.3 Ardisia solanacea Roxb., Hort. Bengal. 16: 580.1814.

Fig. 2a-c

Arbusto 4 a $5 \mathrm{~m}$ alt. Ramos cilíndricos, 2,7-3,1 mm diâm., glabros, com pontuações glandulares lineares. Folhas cartáceas, elípticoobovadas, $15,2-16,2 \times 5,4-5,6 \mathrm{~cm}$, base aguda, ápice acuminado, margem inteira; nervação campilódroma, pontuações glandulares nigrescentes em toda a extensão de ambas as faces; pecíolo 15,2-7,5 mm compr., 1,7-2 mm diâm., atenuado com a lâmina foliar. Inflorescências subterminais e axilares, panículas corimbosas, 4-5 flores; pedúnculo 20-28 mm compr., com pontuações nigrescentes, indumento furfuráceo e tricomas glandulares, de coloração alaranjada. Flores $8-9$ mm compr.; pedicelos 23-25 mm compr., pontuações nigrescentes, lepidotas; sépalas com ca. 6,5× $4 \mathrm{~mm}$, concrescidas na base, largamente ovadas, ápice arredondado, pontuações arredondadas e lineares, margem inteira; corola rotácea, pétalas ca. $8,3 \times 5,5 \mathrm{~mm}$, brevemente conadas na base, subcarnosas, lóbulos elípticos, ápice abruptamente acuminado, margem inteira, com muitas pontuações nigrescentes, cilíndricas e lineares; estames ca. 5,2 mm compr., unidos por um breve tubo; anteras sagitadas, sésseis, ca. 6,2×1,8 mm, rimosas, base cordada, ápice agudo, conectivo nigrescente; ovário elíptico, ca. 1,7 ×1,2 mm compr., multiovulado, estilete $5 \mathrm{~mm}$ compr., com pontuações em toda extensão, estigma puntiforme. Drupa globosa, 5,8-7,8 mm, com pontuações cilíndricas e lineares proeminentes.

Ardisia solanacea é originária da Ásia. Nos estados do Rio de Janeiro e São Paulo é cultivada por seu caráter ornamental, já que possui flores róseas e frutos arroxeados lustrosos. No Rio de Janeiro ocorre como subespontânea na Floresta da Tijuca, matas do Jardim Botânico do Rio de Janeiro e Parque Lage. Ocorre frequentemente em áreas perturbadas e em borda de mata. Floresce e frutifica durante todo o ano.

Material examinado: arboreto do Jardim Botânico do Rio de Janeiro, 30.IV.1999, fl., C. G. Pinto et al. 69 (RB); 7.III.1995, fr., L. C. Giordano et al. 1829 (RB); 31.V.1990, fr., L. C. F. Frutuoso 56 (RB); 24.II.1991, fr., M. Nadruz et al. 670 (RB); matas do Jardim Botânico do Rio de Janeiro, 12.VII.1989, fr., $R$. Marquete et al. s.n. (RB 286864); Floresta da Tijuca, estrada da Vista Chinesa, 21.III.1973, fr., D. Araujo 166 (RB); 25.II.1972, fl. e fr., J. Almeida 1290 (RB); Parque Lage, 29.XII.1967, fl., D. Sucre 2077 (RB).

\section{Cybianthus Mart.}

Arbustos dióicos, com ramos glabros a tomentosos. Folhas pecioladas, atenuadas, cuneadas, com pontuações glandulares translúcidas ou amareladas, margem inteira. Inflorescências laterais, em panículas ou racemos. Flores unissexuais 3-6-meras, cálice e corola valvares ou imbricados, rotáceos a cupuliformes, cartáceos ou carnosos, com pontuações glandulares, tricomas lepidotos, ferrugíneos ou translúcidos. Estames e estaminódios adnatos a corola, filetes formando um tubo estaminal; anteras ovadas, poricidas ou rimosas, introrsas, basifixas ou dorsifixas; estaminódios semelhantes aos estames, menores em tamanho. Estilete cilíndrico, estigma capitado ou puntiforme. Pistilódio cônico ou vestigial; placenta com óvulos unisseriados. Drupa globosa a globosadepressa, monospérmica, com pontuações cilíndricas e ou lineares pouco visíveis. 

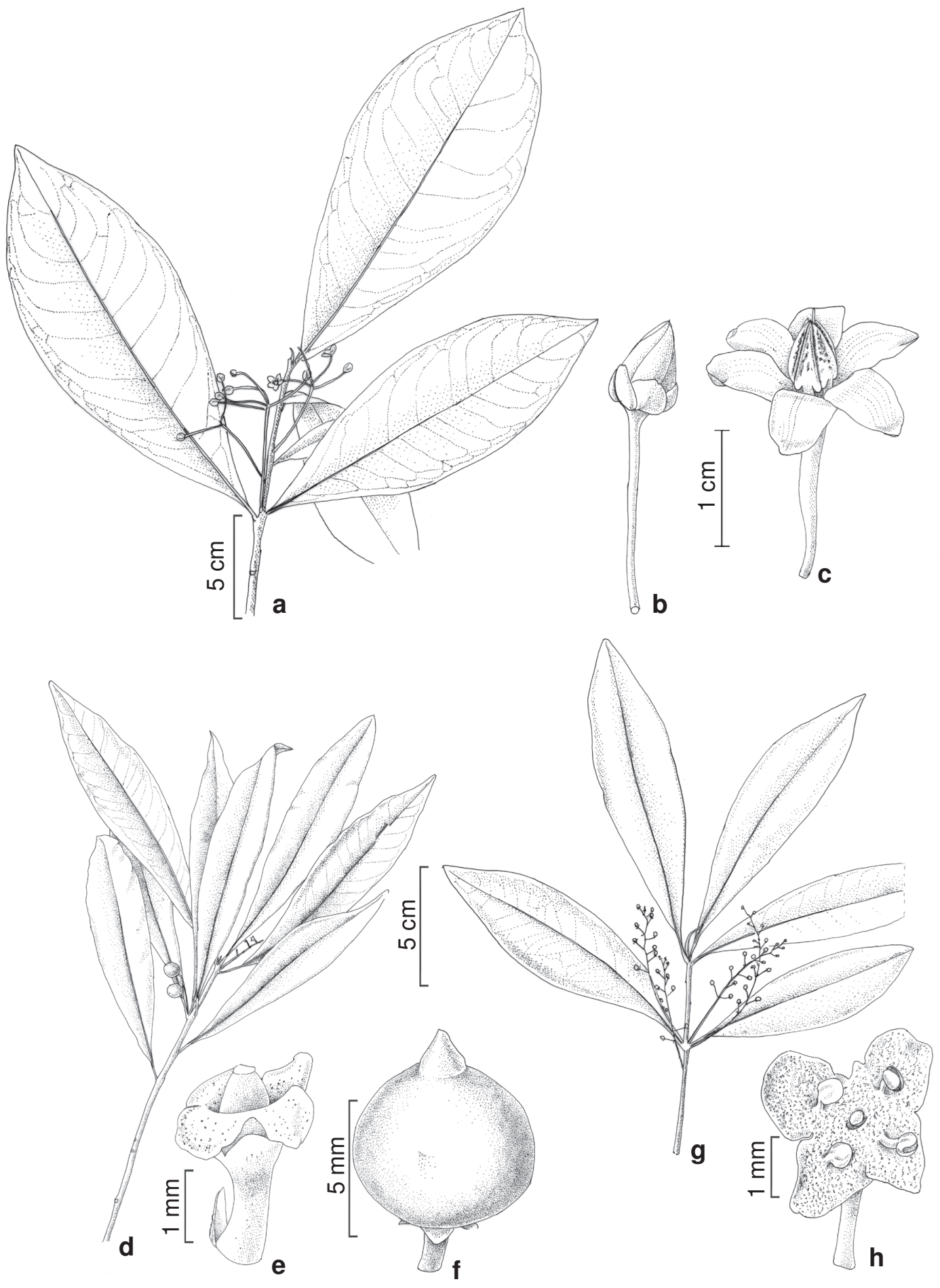

Figura 2 - a-c. Ardisia solanacea Roxb. - a. ramo florífero; b. botão floral; c. flor; d-h. Cybianthus cuneifolius Mart. - d. ramo com frutos imaturos; e. flor pistilada; f. fruto; g. ramo com botões florais; h. flor estaminada (a-c Sucre 2077; d-f Braga 5786; g-h Sucre 7963). 
Cybianthus possui aproximadamente 200 espécies de distribuição exclusivamente neotropical (Pipoly 1992). No Brasil, está representado por cerca de 40 espécies (Pipoly 1998), a maioria pertencente ao subgênero Cybianthus (Agostini 1980).

2.1 Cybianthus cuneifolius Mart., Nov. Gen. et Sp. 3: 88. 1829.

Fig. 2d-h

Arbustos unicaules, 1,5-2 m alt. Ramos terminais cilíndricos, candelabriformes, $1,7-3 \mathrm{~mm}$ diâm., tomentoso-ferrugíneo nas porções jovens. Folhas lanceoladas, $9-15 \times 1,5-3 \mathrm{~cm}$, membranáceas a cartáceas; base cuneada, ápice agudo-acuminado, nervação broquidódroma, pontuações circulares e nigrescentes na face abaxial; margem inteira, revoluta; pecíolo 6$10 \mathrm{~mm}$ compr., glabro. Inflorescências em racemos terminais e laterais, 3,5-4 cm compr., uma em cada axila foliar, com 6-10 flores, indumento tomentosoferrugíneo. Flores 4-meras, raro 3-5-meras; bractéolas ca. 0,5 $\mathrm{mm}$ compr., lanceoladas, margem irregular; sépalas cartáceas, $0,8 \times 0,5 \mathrm{~mm}$, ápice arredondado a agudo, curtamente conatas na base; pétalas cartáceas, ca. 1,8 × 1,5 mm, suborbiculares, pontuações cilíndricas, alaranjadas e nigrescentes, ápice arredondado, margem irregular com tricomas capitados; pedicelos 3,5$3,7 \mathrm{~mm}$ compr. em flores estaminadas, $1,5-2 \mathrm{~mm}$ compr. em flores pistiladas; estames ca. 1,2 mm compr.; filetes ca. 0,5 mm compr., anteras ca. 0,8 $\times 1 \mathrm{~mm}$, ovadas, deiscentes por poros apicais, dorsifixas, conectivo ferrugíneo; pistilo cônico, estilete ca. $0,5 \mathrm{~mm}$ compr., estigma subcapitado. Drupa globosa, $5 \times 4,6 \mathrm{~mm}$, com pontuações lineares, nigrescentes e proeminentes.

Cybianthus cuneifolius ocorre como arbustos que ocupam preferencialmente florestas úmidas e sombreadas de encosta, em altitudes variando de $500-800 \mathrm{~m}$. Os ramos são caracteristicamente candelabriformes e as flores apresentam coloração amarelo-pálida, sendo esverdeadas no centro. Floresce nos meses de novembro a janeiro e frutifica no mês de janeiro. Material examinado: Floresta da Tijuca, Morro Sumaré, 11.XI.2002, fl., D. Fernandes etal. 611 (RB);24.XI.1971, fl., D. Sucre 7963 (RB); 22.XII.1971, fl., D. Sucre 8158 (RB); 21.I.2002, fr., D. Fernandes 666 (RB); Horto Florestal, 24.IX.1991, fl., M. Nadruz et al. 703 (RB); Matas do Pai Ricardo, 7.XI.1945; fl., P. Occhioni 250 (RB); Parque Nacional da Tijuca, Pedra da Gávea, 29.I.2000, fl. e fr., J. M. A. Braga 5786 (RB).

\section{Myrsine L.}

Arbustos, arvoretas ou árvores, dióicas. Ramos terminais cilíndricos, glabros a tomentosos. Folhas pecioladas, elípticas, ovadas a lanceoladas; com pontuações glandulares translúcidas, margem inteira. Inflorescências laterais e umbeliformes. Flores unissexuais, 46-meras, cálice e corola valvares a imbricados, rotáceos, raro cupuliformes, com pontuações glandulares alaranjadas a nigrescentes, membranáceas a cartáceas, tricomas capitados na margem, translúcidos. Estames e estaminódios adnatos a corola, filetes formando um tubo estaminal também adnato a corola, raro tubo estaminal parcialmente livre da corola, com apêndices alternos aos estames; anteras ovadas, rimosas, introrsas, dorsifixas; anteródios sagitados, menores que os estames. Estilete inconspícuo, estigma longo, irregularmente ramificado. Ovário globoso a elíptico, placenta com óvulos unisseriados, pistilódio cônico, estigma vestigial. Drupa globosa a elíptica, com pontuações cilíndricas e/ou lineares, abundantes.

Myrsine é um gênero com cerca de 300 espécies de distribuição pantropical, dentre elas cerca de 35 ocorrem no Brasil (Mez 1902).

\section{Chave para identificação das espécies de Myrsine}

1. Ramos terminais totalmente cobertos por longos tricomas ferrugíneos, ramificados, visíveis; folhas membranáceas 3.1 M. coriacea

1'. Ramos terminais glabros, ou glabriúsculos, com tricomas esparsos, curtos e não ramificados, pouco visíveis, somente na porção apical; folhas cartáceas a coriáceas.

2. Folhas coriáceas, ovadas a elípticas, com pontuações lineares abundantes em toda face abaxial, nervuras secundárias pouco evidentes; cálice cupuliforme; frutos globosos ........ 
2'. Folhas cartáceas a coriáceas, ovadas, elípticas a lanceoladas, pontuações esparsas no limbo, raras ou evidentes na nervura principal, nervuras secundárias pouco a muito evidentes; cálice rotáceo; frutos globosos a elípticos.

3. Folhas ovado-lanceoladas, base aguda, ápice agudo a acuminado, pontuações evidentes na nervura principal; pecíolo 7-10 mm compr.; pedicelos 2-5 mm compr.; frutos elípticos, $7 \times 9 \mathrm{~mm}$ 3.3 M. hermogenesii

3'. Folhas ovadas a elípticas, base e ápice arredondado, obtusos a agudo-acuminados, pontuações pouco evidentes ou visíveis no limbo; pecíolo 5-20 mm compr.; pedicelos 3$10 \mathrm{~mm}$ compr.; frutos globosos, $5 \times 7 \mathrm{~mm}$.

4. Pontuações visíveis e esparsas no limbo, nervura principal ca. $1 \mathrm{~mm}$ larg. na base da face abaxial, nervuras secundárias evidentes; inflorescências congestas nos ramos, pedicelos 6-10 mm compr. 3.4 M. umbellata

4'. Pontuações raras a não visíveis no limbo, nervura principal 1,5-2 mm larg. na base da face abaxial, nervuras secundárias pouco evidentes; inflorescências esparsas nos ramos, pedicelos $3-5 \mathrm{~mm}$ compr. 3.2 M. guianensis

3.1 Myrsine coriacea (Sw.) R.Br. ex Roem. $\&$ Schult., Syst. veg. 4: 511.1819. Fig. 3a-b

Arbustos a arvoretas ca. 3-10 m alt. Ramos terminais, 2-3 mm diâm., com indumento ferrugíneo. Folhas (3-)6-8(-10) × 1,5-2 cm, membranáceas, base aguda, revoluta na face abaxial, ápice agudo-acuminado; pontuações pouco visíveis; pecíolo 5-10 mm compr., piloso. Inflorescências com 6-8 flores, flores 5-meras, 2-3,5 mm compr.; pedicelos $1-1,5 \mathrm{~mm}$ compr., sépalas $0,5-0,8 \mathrm{~mm}$ compr., ápice agudo, margem fimbriada; pétalas (1-)2-2,5 mm compr., com pontuações globosas, escuras; apêndices do tubo estaminal ausentes, anteras $1-1,5 \mathrm{~mm}$ compr., anteródios $0,8 \mathrm{~mm}$ compr.; ovário ca. $0,8 \times 1,0 \mathrm{~mm}$, estigma ca. $1 \mathrm{~mm}$ compr. Drupa globosa ca. $3 \times 4 \mathrm{~mm}$, com pontuações lineares nigrescentes e proeminentes.

Myrsine coriacea é uma espécie que ocorre comumente em diversas formações florestais do Brasil, considerada pioneira nos estágios sucessionais. Ocorre preferencialmente em regiões abertas e na orla da mata. As folhas e ramos terminais são cobertos total ou parcialmente por tricomas ramificados, de colocação ferrugínea. É conhecida popularmente como capororoca.

Material examinado: Alto da Boa Vista, av. Edson Passos, próximo ao Leão, 27.IV.1984, fl., C.A. L. Oliveira et al. 40 (GUA); 6.VII.1984, fr., M. C. Vianna 1648 (GUA); estrada das Canoas, VI.1960, fl., A. P. Duarte 5256 (HB, HBR); VI.1985, fr., M. Nadruz 269, 270 (RB); estrada da Mesa do Imperador ao Alto da Boa Vista, 26.III.1959, fl., E. Pereira et al. 4541 (HB, RB); Horto Florestal, 29.IV.1977, est., Pessoal do Horto Florestal s.n. (RB 152828); Mesa do Imperador, 1.V.1951, fl., E. Pereira 640 (RB); Mesa do Imperador, estrada da Vista Chinesa, 22.VII.1977, fr., A. M. S. F. Vaz 205 (RB); Parque Nacional da Tijuca, 10.XI.1984, fl., $V$. F. Ferreira 3603 (GUA); Pedra da Onça, estrada do Redentor, 22.VI.1959, fl., A. P. Duarte 4875 (HB, RB); Vista Chinesa, 14.V.1935, est., A. C. Brade 14493 (RB); 20.V.1958, fr., E. Pereira et al. 4315 (HB); 20.V.1958, fr., Liene 3770 (RB); 22.VIII.1995, fl., C. A. L. Oliveira 1046 (GUA); próximo a FEEMA, 28.VIII.1996, fl., D. Araújo 10471 (GUA).

3.2 Myrsine guianensis (Aubl.) O. Kuntze, Rev. Gen. 2: 402.1981. Fig. 3c-e Arvoretas a árvores (3-)5-8 m alt. Ramos terminais, 2-3 mm diâm., glabros. Folhas 9-15×1,5-3 cm, cartáceas a coriáceas, ovadas a elípticas, base obtusa, revoluta na face abaxial, ápice agudo-arredondado; nervura principal proeminente, $1,5-2 \mathrm{~mm}$ larg. na base, secundárias pouco evidentes, pontuações raras ou não visíveis, esparsas; pecíolo 8-15(-20) $\mathrm{mm}$ compr., glabro. Inflorescências esparsas nos ramos com 6-8 flores; flores 5-meras, 4$6 \mathrm{~mm}$ compr.; pedicelos 3-5 mm compr.; sépalas ca. $1 \mathrm{~mm}$ compr., ápice agudo, margem fimbriada; pétalas 2,5-3 $\mathrm{mm}$ compr., com pontuações globosas, escuras; apêndices do tubo estaminal ausentes, anteras e anteródios ca. 1,5 mm compr.; ovário ca. $5 \mathrm{~mm}$ compr., 


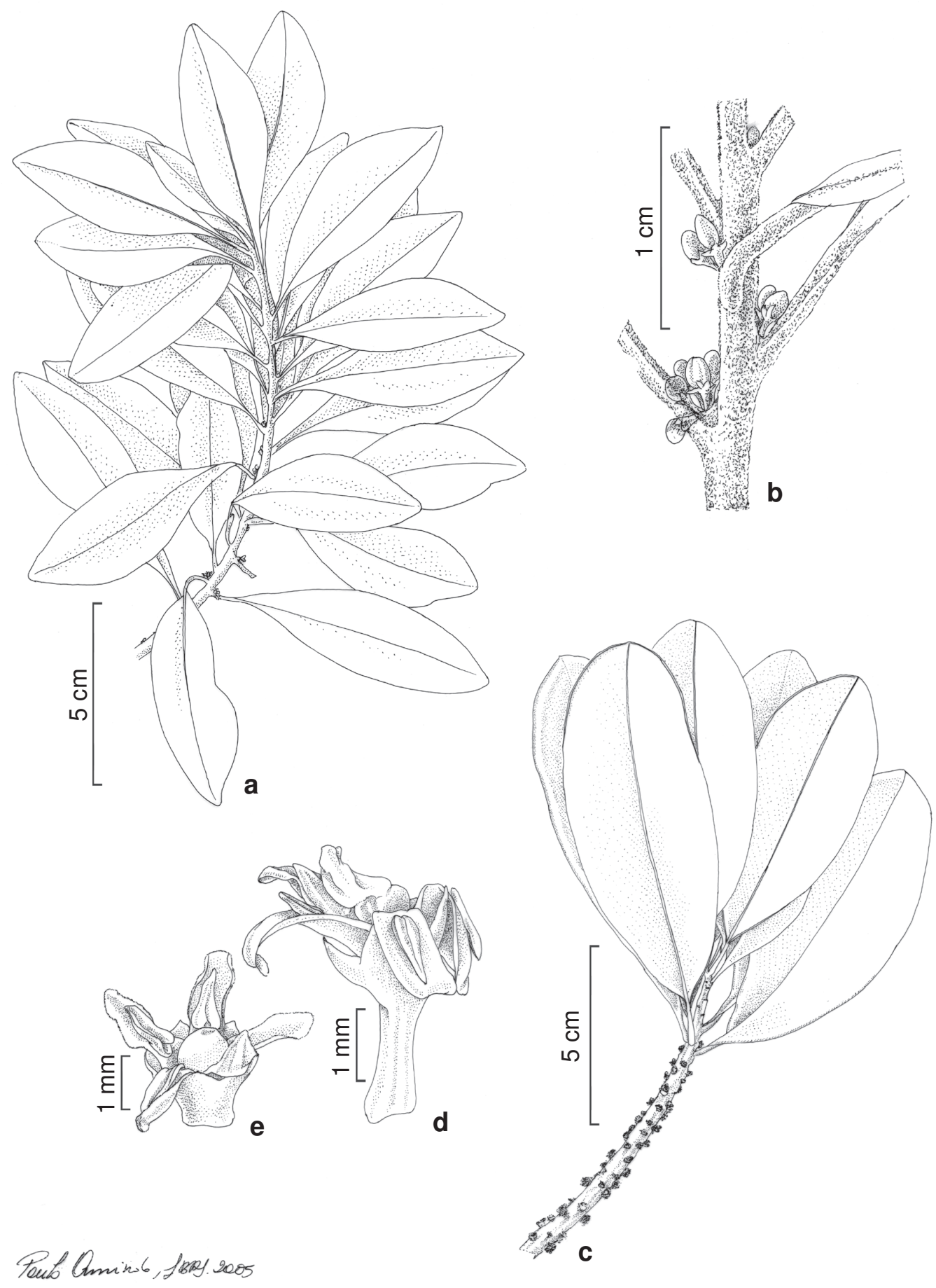

Figura 3 - a-b. Myrsine coriacea (Sw.) R.Br. ex Roem. \& Schult. - a. ramo; b. detalhe de um ramo com botões; c-e. Myrsine guianensis (Aubl.) O. Kuntze - c. ramo; d. flor pistilada com pedicelo curto, ovário com estigma; e. flor pistilada com pedicelo longo, ovário com estigma (a-b Pereira 640; c-d Duarte 4882; e Nadruz 251). 
estigma ca. $1 \mathrm{~mm}$ compr. Drupa globosa ca. 5 $\times 7 \mathrm{~mm}$, com pontuações lineares nigrescentes.

Myrsine guianensis ocorre da região Amazônica ao Rio Grande do Sul, sendo comumente encontrada em formações vegetais de restinga da costa brasileira. Diferencia-se de M. umbellata por apresentar folhas muito coriáceas, pedicelos curtos e nervuras secundárias inconspícuas. Geralmente, os espécimes de $M$. monticola Mart. que ocorrem no cerrado e campos rupestres, são identificados como M. guianensis.

Material examinado: Corcovado, próximo ao Cristo, 2.VI.1948, fr., A. P. Duarte 1125 (RB); entre a Mesa do Imperador e Alto da Boa Vista, 22.VI.1959, fl., $A$. P. Duarte 4882 (RB, SP); estrada entre Tijuca e Paineiras, 21.VIII.1931, fr., J. G. Kulhmann 530 (RB); Jardim Botânico, 26.VII.1916, est., D. Constantino 214 (RB); Estrada das Canoas, VI.1985, fl., $M$. Nadruz 251 (RB); praia da Gávea, VII.1916, est., A. Frazão s.n. (RB 12641); Mata do Rumo, Horto Florestal, 4.VI.1927, fl., Pessoal do Horto Florestal s.n. (RB 152824).

3.3 Myrsine hermogenesii (Jung-Mendaçolli \& Bernacci) M.F. Freitas \& L.S. Kinoshita, Bradea 10(1): 2. 2004.

Fig. 4a-b

Arvoreta a árvores 6-10 m alt. Ramos terminais 3-4 mm diâm., glabros. Folhas 14$19 \times 3-5 \mathrm{~cm}$ compr., cartáceas a coriáceas, ovado-lanceoladas, base aguda, ápice agudoacuminado; pontuações avermelhadas, evidentes na nervura principal; pecíolo 7-10 mm compr., glabro. Inflorescências com 6-8 flores, 5-meras, 5-6 mm compr.; pedicelos 2$5 \mathrm{~mm}$ compr., sépalas ca. $1 \mathrm{~mm}$ compr., ápice agudo, margem fimbriada; pétalas 3,5-4 mm compr., com pontuações globosas e elípticas, escuras; apêndices do tubo estaminal ausentes, anteras 1,5-2 mm compr., anteródios 1,5 mm compr.; ovário elíptico-globoso 1,8-2×1 mm, estigma 2-2,5 $\mathrm{mm}$. Drupa elíptica ca. $7 \times 9$ $\mathrm{mm}$, com pontuações lineares nigrescentes.

Myrsine hermogenesii ocorre em floresta ombrófila do sul da Bahia ao Rio Grande do Sul. É diferenciada das demais espécies, especialmente de M. umbellata, por apresentar a nervura principal dotada de numerosas pontuações com coloração avermelhada, tornando-se marrom no material herborizado. Apresenta também frutos com maior tamanho que as demais espécies conhecidas deste gênero no Brasil.

Material examinado: Vista Chinesa, fr., 23.VIII.1931, A. C. Brade 11009 (RB).

Material adicional examidado: BRASIL. RIO DE JANEIRO: Petrópolis, Quitandinha, 1948, fl., O. C. Goes et al. 87 (RB).

3.4 Myrsine umbellata Mart., Flora Beibl. Ser 2, 24. 1841.

Fig. 4c-d

Arvoretas a árvores $1,5 \mathrm{a} 2 \mathrm{~m}$ alt. Ramos terminais 2-3 mm diâm., glabra. Folhas 9-15 $\times 1,5-3 \mathrm{~cm}$, cartáceas a coriáceas, ovadas a elípticas, base aguda, revoluta na face abaxial, ápice agudo a acuminado, nervura principal ca. $1 \mathrm{~mm}$ larg., nervuras secundárias evidentes; pontuações visíveis e esparsas no limbo; pecíolo 5-10 mm compr., glabro. Inflorescências com 6-8 flores, flores 5-meras, 2-3,5 mm compr.; pedicelos 6-10 mm compr., sépalas $0,5-0,8 \mathrm{~mm}$ compr., ápice agudo, margem fimbriada; pétalas (1-)2-2,5 mm compr., com pontuações globosas, escuras; apêndices do tubo estaminal ausentes, anteras 1-1,5 mm compr., anteródios $0,8 \mathrm{~mm}$ compr.; ovário ca. $0,8 \times 1 \mathrm{~mm}$, estigma ca. $1 \mathrm{~mm}$ compr. Drupa globosa ca. $5 \times 7 \mathrm{~mm}$, com pontuações lineares nigrescentes e proeminentes.

Myrsine umbellata apresenta ampla distribuição no Brasil, ocorrendo principalmente na mata atlântica e cerrado. Caracteriza-se particularmente por suas densas inflorescências caulinares com longos pedicelos.

Material examinado: s.1., 4.VI.1944, fl., E. Pereira 394 (RB); alto do Corcovado, 28.IX.1964, fr., $B$. Blaster et al. 1135 (R); Horto Florestal, 8.X.1992, fr., R. Marquete et al. 672 (RB); Horto Florestal do Cantagalo, 10.II.1993, fr., M. Kawall 307 (MBM); Jardim Botânico do Rio de Janeiro, 29.VII.1933, fl., P. Occhioni s.n. (RB 110916); 28.VII.1947, fl., J. G. Kuhlmann s.n. (RB 60580).

Material adicional examinado: BRASIL. RIO DE JANEIRO: Petrópolis, Mata do Judeu, 7.XII.1968, fr., D. Sucre et al. 4240 (RB); Visconde de Mauá, Vale das Flores, 20.VI.1999, fr., A. Lobão 428 (RB). 


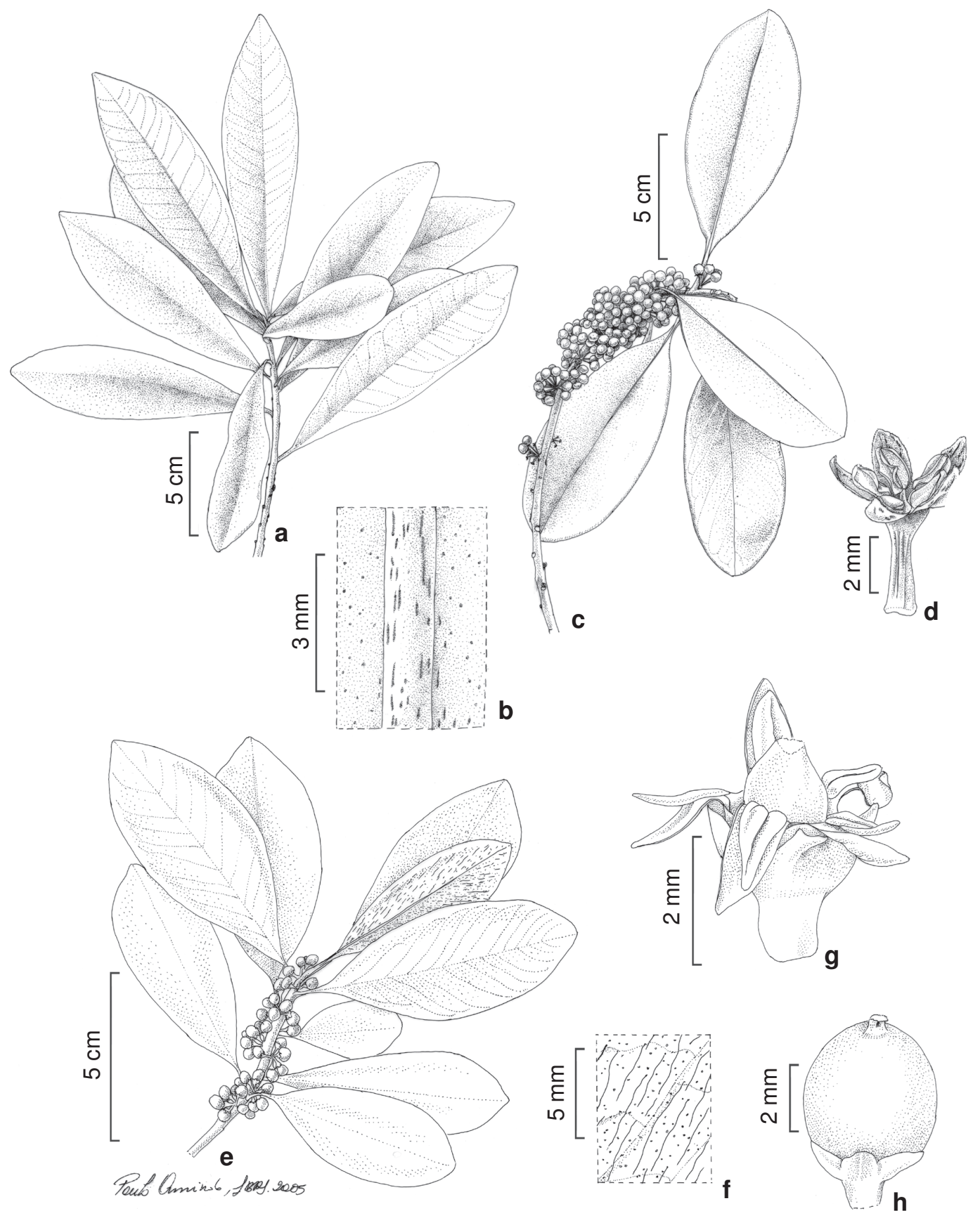

Figura 4 - a-b. M. hermogenesii (Jung-Mendaçolli \& Bernacci) M.F.Freitas \& L.S.Kinoshita - a. ramo; b. detalhe da face abaxial foliar mostrando estrias das cavidades secretoras internas na nervura principal e pontuações de tricomas glandulares no limbo. c-d. M. umbellata Mart. - c. ramo com frutos; d. flor estaminada. e-h. M. venosa A. DC.: e. ramo com frutos; f. detalhe da face abaxial foliar com tricomas glandulares e cavidades secretoras alongadas; g. flor pistilada com fruto em desenvolvimento; h. fruto imaturo (a-b Brade 11009; c Sucre 4240; d Lobão 428; e-h Pessoal do Horto Florestal RB 152829). 
3.5 Myrsine venosa A. DC., Ann. Sc. Nat. ser. 2. 5(16): 86. 1841.

Fig. $4 \mathrm{e}-\mathrm{h}$

Arbustos 3-5 m alt. Ramos terminais ca. 3 mm diâm., glabros. Folhas 10-12×7-9 cm, coriáceas, ovadas a elípticas, base aguda a obtusa, ápice agudo-acuminado; pontuações lineares abundantes na face abaxial do limbo foliar, nervuras secundárias pouco evidentes; pecíolo 1-1,5 mm compr., glabro. Inflorescências com 10-12 flores, flores 5-meras, 4-5 mm compr.; pedicelos 1-2 mm compr., cálice cupuliforme, sépalas 1-2 mm compr., ápice agudo, margem fimbriada; pétalas $0,3-0,4 \mathrm{~mm}$ compr., com pontuações globosas, escuras; apêndices do tubo estaminal ausentes, anteras $2-2,2 \mathrm{~mm}$ compr., anteródios 1,1-5 mm compr.; ovário ca. $1 \times 1 \mathrm{~mm}$, estigma ca. $1,3 \mathrm{~mm}$ compr. Drupa globosa ca. $5 \times 6 \mathrm{~mm}$, com pontuações lineares nigrescentes e pouco visíveis.

Myrsine venosa ocorre do estado de Pernambuco até Santa Catarina em formações vegetais de campos rupestres e restinga. As folhas apresentam na face abaxial cavidades secretoras hialinas, tornando-se nigrescentes após a desidratação.

Material examinado: Alto da Boa Vista, VI.1960, fl., A. P. Duarte 5241 (HB); estrada da Vista Chinesa, 15.IX.1982, fl., H. F. Martins 578(GUA); 12.V.1991, fl., C.A. L. Oliveira 401 (GUA); 31.V.1993, fl., D. Araújo 9821 (GUA); 5.XII.2002, fr., D. Fernandes 638 (RB); estrada do Redentor, Serra Carioca, 22.VI.1941, fl., A. C. Brade 16833 (RB); estrada do Corcovado, 23.IX.1958, fl., E. Pereira et al. 4314 (HB); Gávea
Pequena, cabeceira do vale, 29.V.1963, fl., H. E. Strang 526 (GUA); Gericinó, 800 m s.m., 24.V.1931, fl., A. C. Brade 10848 (R); Horto Florestal, 3.VI.1927, fr., Pessoal do Horto Florestal s.n. (RB 152829).

\section{Stylogyne A.DC.}

Arbustos dióicos, androdióicos, polígamos ou bissexuais. Ramos glabros, raro pilosos nas porções jovens. Folhas pecioladas, atenuadas, com pontuações glandulares translúcidas ou nigrescentes, margem inteira. Inflorescências estritamente terminais, ou terminais e subterminais, ou subterminais e axilares, axilares e ramifloras, ou estritamente axilares, paniculado-corimbosas, corimbosas ou fasciculadas. Flores bissexuais ou unissexuais 4-5-meras, cálice e corola contorto-dextrorsos, pontuados. Estames livres entre si, anteras introrsas, basifixas ou dorsifixas, deiscentes por fendas laterais curtas e ápice dilatado ou por fendas laterais longas. Estilete cilíndrico, estigma capitado ou capitulado. Drupa esférica ou esferoidal, monospérmica, embrião filiforme, transverso.

Stylogyne é exclusivamente neotropical e possui entre 60-70 espécies (Pipoly \& Ricketson 2000) predominantes na América do Sul (Ricketson \& Pipoly 2003). A única revisão realizada para o gênero (Mez 1902) citou 28 espécies para o Brasil, das quais oito ocorrem no estado do Rio de Janeiro (Carrijo \& Freitas 2008).

\section{Chave para as espécies de Stylogyne}

1. Inflorescências terminais; flores 5-meras S. laevigata

1'. Inflorescências axilares e ramifloras; flores 4-meras S. depauperata

4.1 Stylogyne depauperata Mez in Engl., Das Pflanzenreich 4(236): 277. 1902. Fig. 5a-c Arbustos ou árvores, 5-6 m alt. Ramos cilíndricos, 2,6-3,9 mm diâm., glabros. Folhas cartáceas, oblongo-elíptica a elíptico-obovada, $15,6-16,2(-22,5) \times 6,2-7,2(-8,7) \mathrm{cm}$, glabras; base arredondada a aguda, ápice arredondado, agudo ou ligeiramente acuminado; nervuras secundárias unidas por arcos inconspícuos próximos às margens; margem inteira, revoluta; pecíolo canaliculados, 6-9 mm compr., 2,2-2,8 mm diâm., glabros. Inflorescências axilares e ramifloras, corimbosas, 11,3-13,5(15) mm compr., bipenadas. Flores bissexuais e estaminadas, 4-meras, 3,44 mm compr.; pedicelos cilíndricos, 2,8-3,2 mm compr., glabros; sépalas cartáceas, ovadas, $1-$ $1,2 \times 0,9-1 \mathrm{~mm}$, fusionadas na base, lobos eretos, ápice largamente arredondado, superfície rugosa, 


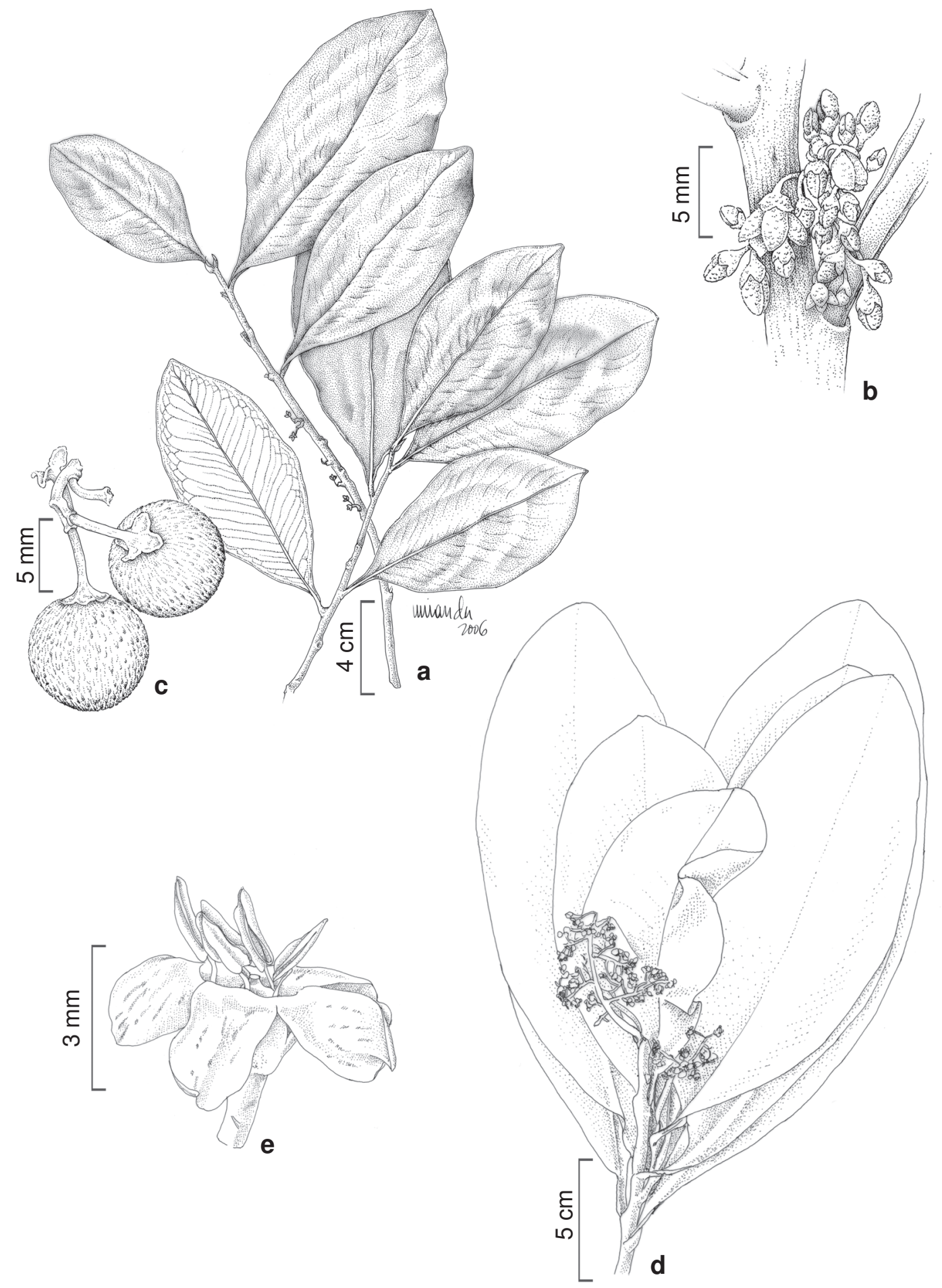

Figura 5 - a-c. Stylogyne depauperata Mez - a. ramo florífero; b. detalhe da inflorescência no ramo; c. frutos. d-e. Stylogyne laevigata (Miq. ex Mart.) Mez - d. ramo florífero; e. flor (a Rego 896; b Sucre 4461 \& Braga 1338; c Marquete 2990; d-e Duarte 294). 
margem distintamente hialina, levemente irregular; corola campanulada, pétalas 3,6-4 mm compr., cartáceas, glabras; lobos 2,7-3×1,6-1,7 mm, elípticos, simétricos, ápice arredondado, margem distintamente hialina, levemente irregular; flores estaminadas com estames 2,52,9 mm compr., filetes ligulados, 1,2-1,5 mm compr., adnatos ca. 1,2 $\mathrm{mm}$ acima da base do tubo da corola; anteras elíptico-lanceoladas, 2,0-2,3 ×0,8-1,0 mm, rimosas com ápice dilatado, base cordada, ápice obtuso a agudo, apiculado; pistilódio 1,4-1,7 mm compr., cônico; flores bissexuais com estames 1,8-2,0 mm compr., filetes 1,2-1,5 mm compr., anteras 1,5-1,9×0,5$0,8 \mathrm{~mm}$, rimosas com ápice alargado; ovário ampuliforme, ca. $0,9 \times 0,5 \mathrm{~mm}, 4-5$ óvulos unisseriados, estilete cilíndrico, 1,3-1,6 mm compr., estigma capitado. Drupa esferoidal, 6,7-7,3 $\times$ $6,7-7,1 \mathrm{~mm}$, pericarpo com densas pontuações lineares nigrescentes.

Stylogyne depauperata apresenta distribuição restrita ao estado do Rio de Janeiro (Carrijo \& Freitas 2008). São arbustos de ramos candelabriformes e lenticelados, folhas cartáceas com pontuações translúcidas, inflorescências pêndulas e flores de coloração creme. S. depauperata é muito frequiente na localidade do Parque Nacional da Tijuca conhecida como 'Matas do Pai Ricardo', onde populações de indivíduos em diferentes estádios de desenvolvimento apresentam padrão de distribuição agregado.

Material examinado: próximo à Tijuca, 29.XII.1869, fl., A. F. Glaziou 4073 (R); Parque Nacional da Tijuca, Mata do Rumo, 19.I.1969, fl. e fr., D. Sucre 4461 \& P. I. S. Braga 1338 (RB).

4.2 Stylogyne laevigata (Miq. ex Mart.) Mez in Mart., Fl. bras., 10:285. $1856 . \quad$ Fig. 5d-e

Arbustos 5-10 m alt. Ramos cilíndricos, 0,5-0,6 mm diâm., glabros. Folhas cartáceas, elípticas e oblongas à oblongo-obovatas, (18-) 20-22,5(-26,8) ×(6,5-)8,-9,5 cm, glabras; base atenuada, ápice arredondado ou agudo, margem inteira, revoluta; nervação camptobroquidódroma; margem inteira. pontuações glandulares, cilíndricas, nigrescentes; pecíolo canaliculado, 14-17,3(-25) cm compr., glabros. Inflorescências terminais, paniculado-corimbosas, (3)5-6(7). Flores bissexuais, 5-meras, (4,4-)5,5-6 mm compr.; pedicelos cilíndricos, 2-2,6 mm compr., glabros; sépalas cartáceas, ovais, 1,3-1,8×0,8$0,9 \mathrm{~mm}$, fusionadas na base, lobos eretos, ápice arredondado à agudo, margem inteira, uniforme; corola campanulada, pétalas 4,2-4,5 mm compr., cartáceas, glabras; lobos 2,8-3×1,6-1,7 mm, elípticos, assimétricos, ápice abruptamente acuminado, margem uniforme; estames ca. 2,2 $\mathrm{mm}$, filetes 1-1,3 mm compr., filetes aderidos na base da corola, anteras $1,9 \times 0,7 \mathrm{~mm}$, rimosas; ovário elíptico-ovado, ca. 1,6 × 0,8 mm, 3-4 óvulos, unisseriados, estilete cilíndrico, 1,8-2,1 mm compr., estigma capitulado. Drupa esferoidal, 6$6,5 \times 7-7,5 \mathrm{~mm}$, pericarpo com pontuações elípticas e circulares nigrescentes.

Stylogyne laevigata apresenta distribuição restrita aos estados do Rio de Janeiro e São Paulo (Jung-Mendaçolli et al. 2005; Carrijo e Freitas 2008). Na vegetação do Horto Florestal, ocorre em floresta de encosta de formações secundária em altitudes de 100 a 800 m s.m. Floresce de agosto a setembro e frutifica de setembro a dezembro.

Material examinado: mata do Pai Ricardo, 14.II.1945, fr., P. Occhioni 249 (RB); Gávea Pequena, 18.IX.1946, fl., A. P. Duarte 294 (R, RB); mata da Gávea, 20.IX.1946, fl., P. Ochioni 705 (RB); mata da Lagoinha, 21.VIII.1968, fl., D. Sucre 3571 (RB); Corcovado às Paineiras, IX.1884, fl., Glaziou 15185 (R); Horto Florestal, s.d, fl., J. G. Kuhlmann s.n. (RB 152817).

\section{Agradecimentos}

À Fundação de Amparo a Pesquisa do Estado do Rio de Janeiro (FAPERJ) pelo auxílio a pesquisa concedido à primeira autora, modalidade Instalação (INST); aos curadores dos herbários consultados; à Dra. Rejan Rodrigues Guedes-Bruni (JBRJ) pelas sugestões, a Paulo Ormindo, pelas ilustrações, e à CAPES pelas Bolsas de Mestrado e Doutorado concedidas à segunda autora.

\section{REFERÊNCIAS BibLIOGRÁFICAS}

Agostini, G. 1980. Uma nueva clasificación del género Cybianthus (Myrsinaceae). Acta Biologica Venezuelica 10(2): 129-185. 
Aublet, J. B. C. F. 1775. Histoire des plantes de la Guiane Francoise. Paris, 976p.

Barroso, G. M.; Peixoto, A. L.; Ichaso; C. L. F.; Guimarães, E. F. \& Costa, C. G. 2002. Sistemática de Angiospermas do Brasil. Vol. 1. $2^{a}$ ed. Editora da Universidade Federal de Viçosa, Viçosa, 443p.

Carrijo, T. T. \& Freitas, M. F. 2008. Stylogyne (Myrsinaceae) no estado do Rio de Janeiro. Rodriguésia 59(2): 343-360.

Chen, C. \& Pipoly, J. J. 1996. Myrsinaceae. In: Zheng-yi, W. \& Raven, P. (eds.). Flora of China. Vol. 15. Science Press, Beijing, and Missouri Botanical Garden, St. Louis. Pp. 1-38.

Dorneles, L. P. P. \& Negrelle, R. R. B. 2000. Aspectos da regeneração natural de espécies arbóreas da Floresta Atlântica. Iheringia 53: 85-100.

Freitas, M. F. \& Kinoshita, L. S. 2004. New combinations of brazilian Myrsine (Myrsinaceae). Bradea 1(10): 1-7. 2005. Novas espécies de Myrsine (Myrsinaceae) para o Brasil. Rodriguésia 56(87): 67-72.

Gentry, A. H. 1996. A field guide to the families and genera of woody plants of Northwest, South America (Colombia, Ecuador, Peru) with supplementary notes on herbaceous taxa. Conservation International. University of Chicago Press, 895p.

Heywood, V. H. 1993. Flowering plants of the world. Oxford University Press, New York, 335p.

Holmgren, P. K.; Holmgren N. H. \& Barnett, L. C. 1990. Index Herbariorum, Part 1: The herbaria of the world, 8th ed. Regnum Vegetabile. Vol. 120. New York Botanical Gardem, New York, 693p.

Hosaka, E. Y. 1940. A revision of Hawaiian species of Myrsine (Suttonia, Rapanea), Myrsinaceae. Occasional papers of Bernice Bishop Museum. Hawaii 16: 25-76.

Jackes, B. 2005. Revision of Myrsine (Myrsinaceae) in Australia. Australian Systematic Botany 18: 399-438.
Jung-Mendaçolli, S. L. \& Bernacii, L. C. 1997. Myrsinaceae. In: Melo, M. M. R. F.; Barros, F.; Chiea, S. A. C.; Kirizawa, M.; JungMendaçoli, S. L. \& Wanderley, M. G. L. (eds). Flora fanerogâmica da Ilha do Cardoso. Vol. 5. São Paulo Pp. 81-98. .2001. Myrsinaceae da APA do Cairuçu, Parati (Rio de Janeiro, Brasil). Rodriguésia 52(81): 49-64.

Jung-Mendaçolli, S. L.; Bernacii, L. C. \& Freitas, M. F. 2005. Myrsinaceae. In: Wanderley, M. G. L. ; Shepherd, G. J; Melhem, T. S. \& Giulietti, A. M. (eds.). Flora fanerogâmica do estado de São Paulo. Vol. 4. Ed. Rima, São Paulo. Pp. 279-300.

Mez, C. 1902. Myrsinaceae. In: Engler, H. G. A. Das Pflanzenreich. Vol. 9(IV-236) Wilhelm Engelmann, Berlin. Pp. 1-437.

Miquel, F. A. G. 1856. Myrsineae. In: Martius, C. F. P.; Eichler, A. W. \& Urban, I. P. (eds.). Flora brasiliensis 10: 269-338.

Otegui, M. 1998. Sinopsis del gênero Myrsine L. (Myrsinaceae) en el Cono Sur de América del Sur. Candollea 53(10): 133-157.

Pineschi, R. B. 1990. Aves como dispersores de sete espécies de Rapanea (Myrsinaceae) no maciço de Itatiaia, estados do Rio de Janeiro e Minas Gerais. Ararajuba 1: 73-78.

Pipoly, J. J. 1991. Systematic studies in the genus Myrsine L. (Myrsinaceae) in Guyana. Novon 1: 204-210. 1992. The genus Cybianthus subgenus Conomorpha (Myrsinaceae) in Guayana. Annals of the Missouri Botanical Garden 79: 908-957.

1996. Contributions towards a new flora of the Philippines: 1. A synopsis of the genus Myrsine (Myrsinaceae). Sida 17: 115-162.

1998. The genus Cybianthus (Myrsinaceae) in Ecuador and Peru. Sida 18(1): 1-160.

Pipoly, J. J. \& Chen, C. 1995. Nomenclatural notes on the Myrsinaceae of China. Novon 5: 357-361.

Pipoly III, J. J. \& Ricketson, J. M. 2000. Stylogyne aguarunana (Myrsinaceae) a 
new species from Amazonas, Peru. Sida 19(2): 269-273.

Ricketson, J. M. \& Pipoly III, J.J. 2003. A new species of Stylogyne (Myrsinaceae) from Darién, Panamá. Sida 20(3): 919-922.

Silva, N. M.; Valente, M. C; Marquete, R.; Marquete O.; Guimarães, E. F.; Fucks, R. \& Giordano, L. C. S. 1994. Vegetação das áreas do entorno do Jardim Botânico do Rio de Janeiro, Horto Florestal e Parque Lage - 1. Série Estudos e Contribuições. Jardim Botânico do Rio de Janeiro. IBAMA, Rio de Janeiro, 69p.

Silva, J. M. C. \& Tabarelli, M. 2000. Tree species impoverishment and the future flora of the Atlantic forest of northeast Brazil. Nature 404(2): 72-73.
Siqueira, J. C. 1993. O gênero Rapanea Aublet (Myrsinaceae) na região serrana do estado do Rio de Janeiro: aspectos taxonômicos e ecológicos das espécies. Pesquisas Botânica 44: 41-52.

Ståhl, B. \& Anderberg, A. A. 2004. Myrsinaceae. In: Kubtski, K. (ed.). The families and genera of vascular plants VI. Flowering plants dicotyledons. Celastrales, Oxalidales, Rosales, Cornales, Ericales. Springer, Berlin. Pp. 266-281.

Tabarelli, M. \& Mantovani, W. 1997. Colonização de clareiras naturais na floresta atlântica do Sudeste do Brasil. Revista Brasileira de Botânica 20(1): 57-66. 